\title{
Avaliação das silagens de girassol (hibrido m734) obtidas em diferentes épocas de ensilagem pela técnica in vitro semi-automática de produção de gases
}

Luiz Gustavo Ribeiro PEREIRA ${ }^{1}$

Rogério Martins MAURÍClO² Lúcio Carlos GONÇALVES ${ }^{3}$ Thierry Ribeiro $\mathrm{TOMICH}^{4}$ José Avelino Santos RODRIGUES ${ }^{5}$

Norberto Mario

RODRIGUEZ ${ }^{3}$

Correspondências para:

LUIZ GUSTAVORIBEIROPEREIRA Escola de Veterinária

Universidade Federal de Minas Gerais Av. Pasteur 135/1302, Funcionários 30150-290, Belo Horizonte-MG

luizgustavorp@uol.com.br

Recebido para publicação: 31/10/2003 Aprovado para publicação: 15/03/2005

\author{
1 - Departamento de Ciência Animal, Escola de Veterinária, Universidade \\ Federal de Minas Gerais, Belo Horizonte - MG \\ 2 - Fundação Ezequiel Dias \\ 3 - Departamento de Zootecnia da Escola, Veterinária da Universidade \\ Federal de Minas Gerais, Belo Horizonte - MG \\ 4 - Embrapa Pantanal \\ 5 - Embrapa Milho e Sorgo
}

\section{Resumo}

Para que o girassol possa ser utilizado com sucesso na forma de silagem, é necessário que se determine o ponto ideal de ensilagem. O objetivo desse experimento foi avaliar através da técnica in vitro semi-automática de produção de gases a cinética de degradação da matéria orgânica (MO) e matéria seca (MS) das silagens do híbrido M734 ensilado com 100, 107, 114 e 121 dias após o plantio. As leituras de pressão dos gases foram feitas através de um transdutor de pressão às $2,4,6,8,10,12,15$, 19, 24, 30, 36, 48, 72, 96 h pós-inoculação. A cinética ruminal foi descrita matematicamente por meio dos parâmetros: potencial máximo de produção de gases, "lag time", taxa de produção de gases $(\mu)$ e degradabilidade efetiva da MO e MS para diferentes taxas de passagem $(2,5$ e $8 \% / h)$ por um modelo unicompartimental. Verificou-se que o corte da cultura em estádios mais tardios levaram a redução no potencial máximo de produção de gases para a MO $(162,155,144$ e $139 \mathrm{~mL})$ e MS $(138,129,121$ e $119 \mathrm{~mL})$; elevação da "lag time" para $\mathrm{MO}(2,4,2,5,2,8$ e 2,9 h) e MS (2,5, 2,5, 3,0 e 3,0 h); e diminuição do $\mu$ para a $\mathrm{MO}(0,023$, $0,022,0,017$ e $0,017 \mathrm{~mL} / \mathrm{h})$ e MS $(0,022,0,020,0,015$ e $0,016 \mathrm{~mL} / \mathrm{h})$ para as épocas 100,107,114 e 121 dias após o plantio, respectivamente. As épocas mais indicadas para a ensilagem do híbrido M734 foram aos 100 e 107 dias após o plantio.

\section{Introdução}

potencial forrageiro do girassol (Helianthus annuus L.) para produção de silagens vem sendo estudado nos últimos anos e os resultados de pesquisa têm apontado esta cultura como uma boa opção para produção de forragem na época da safrinha e/ou em regiões que apresentem déficit hídrico, pois o girassol apresenta boa tolerância a baixas precipitações pluviométricas, sendo capaz de tolerar períodos secos e produzir silagem de boa qualidade.

Os primeiros estudos sobre o uso do
Palavras-chave:

Girassol.

Produção de gases.

Silagem.

Ponto de ensilagem. girassol na forma de silagem foram baseados em análises bromatológicas, avaliações agronômicas, estudo da dinâmica de fermentação durante o processo de ensilagem, avaliação de aditivos e contribuição das diferentes partes da planta na qualidade e valor nutritivo das silagens. Os resultados desses experimentos têm sido importantes para o balizamento do melhoramento genético dessa cultura na busca de genótipos específicos para produção de silagem. Atualmente, para complementar estes estudos, os experimentos estão concentrados em avaliações envolvendo 
a resposta animal (consumo, digestibilidade, desempenho produtivo) e cinética de degradação.

Apesar de não existir ainda um híbrido de girassol específico para produção de silagens, genótipos destinados à produção de óleo e os materiais confeiteiros designados para produção de sementes comestíveis, vêm sendo avaliados para este propósito. Dentre os genótipos avaliados, o híbrido simples M734 tem se destacado por apresentar algumas características interessantes: boa produtividade, sendo um dos híbridos mais utilizados no Brasil para produção de óleo, o que reflete a sua ampla adaptabilidade à nossas condições; apresenta ciclo intermediário e não tardio, o que o torna menos susceptível às adversidades climáticas dos períodos de safrinha; e tem originado silagens de boa qualidade ${ }^{1,2}$.

Como ferramenta para o estudo da cinética de degradação, a técnica in vitro semiautomática de produção de gases ${ }^{3}$ foi utilizada no presente trabalho para avaliar as silagens de girassol do híbrido M734 ensilado aos 100, 107, 114 e 121 dias após o florescimento.

\section{Materiais e Métodos}

Foram avaliadas as silagens de girassol do genótipo M734 (híbrido simples destinado a produção de óleo, de ciclo intermediário e porte médio) obtidas aos $100,107,114$ e 121 dias após plantio. O girassol, nas respectivas datas foi ensilado em silos de laboratório, confeccionados com tubos de PVC com $40 \mathrm{~cm}$ de comprimento e $10 \mathrm{~cm}$ de diâmetro, com capacidade para aproximadamente $2 \mathrm{~kg}$ de forragem. Os silos foram abertos após 56 dias de fermentação e parte da massa ensilada foi usada para a retirada do suco da silagem, onde foram determinados o $\mathrm{pH}$, utilizandose potenciômetro "Beckman Expandomatic SS-2" e o teor de nitrogênio amoniacal como porcentagem do nitrogênio total $(\mathrm{N}$ $\left.\mathrm{NH}_{3} / \mathrm{NT}\right)^{4}$. A outra parte da silagem foi submetida a pré-secagem em estufa de ventilação forçada a $65^{\circ} \mathrm{C}$ e posterior processamento em moinho com peneira de $1 \mathrm{~mm}$, sendo esta usada para a análise bromatológica [MS de acordo com método da Association Official Analytical Chemists ${ }^{4}$, $\mathrm{PB}$ pelo método de $\mathrm{Kjedhal}^{4}$ e os componentes da parede celular (FDN, FDA, Celulose, hemicelulose e lignina) pelo método seqüencial $\left.{ }^{5}\right]$ e para o ensaio pela técnica in vitro semi-automática de produção de gases ${ }^{3}$.

Foram usados três frascos por tratamento, ou seja, três para cada época de ensilagem (100, 107, 114 e 128 dias) e mais três frascos de brancos (frascos contendo apenas o meio de cultura e o inóculo). Como foram retirados frascos para a determinação da degradabilidade nos tempos 6, 12, 24 e 48 horas, esta seqüência se repetiu por quatro vezes, além dos frascos usados para a leitura dos gases até 96 horas, totalizando 75 frascos.

Foi utilizado meio de cultura composto por solução tampão, macrominerais, microminerais, resazurina e agentes redutores ${ }^{6}$.

A inoculação foi feita usando um pool de líquido ruminal obtido de três ovinos machos castrados, fistulados no rúmen e com aproximadamente dois anos de idade. A dieta destes animais era constituída de feno de "Coast-cross" (Cynodon spp) à vontade e $250 \mathrm{~g} /$ dia de concentrado comercial com $22 \%$ de PB.

A pressão originada pelos gases foi medida através de um transdutor de pressão (tipo T443A, Bailey \& Mackey, Inglaterra). As leituras de pressão foram tomadas as 2 , $4,6,8,10,12,15,19,24,30,36,48,72$ e 96 $\mathrm{h}$ após o início da fermentação. $\mathrm{O}$ volume de gases foi obtido através da relação quadrática existente entre pressão e volume de gases ${ }^{7}$.

A DMS foi obtida após $6,12,24,48$ e 96 horas, através de filtragem do conteúdo de cada frasco em cadinhos de porosidade 1 e posterior secagem em estufa a $100^{\circ} \mathrm{C}$ por 12 horas. A DMO foi calculada a partir da queima dos cadinhos com o resíduo de MS em mufla a $500^{\circ} \mathrm{C}$ por três horas.

$\mathrm{O}$ delineamento experimental foi o de parcelas sub-divididas, onde os frascos foram equivalentes aos blocos, as épocas de 
ensilagem (100, 107, 114 e 121) aos tratamentos e os tempos de incubação de 6 , $12,24,48,72$ e 96 horas às sub-parcelas. Para a comparação das médias de cada tratamento nos diferentes períodos de incubação e das médias dos diferentes períodos de incubação dentro de cada tratamento, utilizou-se o teste de SNK a 5\% de probabilidade.

Os dados de produção cumulativa de gases oriundos da fermentação de cada tratamento foram ajustados através do software Maximun Likelihood Program ${ }^{8}$ ao modelo unicompartimental' $: Y=A\{1$ $\left.\exp p^{[-b(t-L)-c \times(\sqrt{ } t-\sqrt{ } L)]}\right\}$,onde, $Y=$ produção cumulativa de gases (mL); $A=$ assíntota ou potencial máximo de produção de gases; $L=$ tempo de colonização (lag time); $b\left(\mathrm{~h}^{-1}\right)$ e $c\left(\mathrm{~h}^{-0,5}\right)=$ taxas fracionais constantes. Uma taxa fracional $\left(\mathrm{h}^{-1}\right)$ combinada a produção de gases $(\mu)$ foi calculada como: $\mu=b+c / \sqrt{t}$, onde, $\mu=$ taxa de produção de gases $\left(\mathrm{h}^{-1}\right) ; b$ e $c=$ parâmetros semelhantes ao da equação (1); $\mathrm{t}=$ tempo de incubação em horas.

As degradabilidades efetivas (DEMS) empregando as taxas de passagem de 2,5 e $8 \% / \mathrm{h}$ para baixo, médio e alto consumo $^{10}$, foram calculadas pela equação ${ }^{9}$ $D E M S=S_{0} e^{-k T}(1-k I) /\left(S_{0}+U_{0}\right)$, onde, $k=$ taxa de passagem; $S_{0}$ e $U_{0}=$ frações inicialmente fermentáveis e frações não fermentáveis, respectivamente; e $I=\int^{\infty} \exp$ $-[(b+k)(t-T)+c(\sqrt{ } t-\sqrt{T})] d t)$.

\section{Resultados e Discussão}

A composição bromatológica das silagens utilizadas no ensaio de digestibilidade pela técnica in vitro de produção de gases encontra-se na tabela 1 . Os valores de MS variaram de 20,43 a $61,63 \%$ e aumentaram em decorrência do estádio de maturação. Os valores de $\mathrm{PB}$ estiveram próximos a $11 \%$ e aparentemente não foram influenciados pela época de ensilagem. Quanto às frações fibrosas, observam-se valores próximos de FDN e FDA para as três primeiras épocas, enquanto a silagem obtida aos 121 dias apresentou os valores mais elevados. Os valores de $\mathrm{pH}$ e $\mathrm{N}-\mathrm{NH}_{3} / \mathrm{NT}$ não puderam ser calculados para a silagem obtida após 121 dias do plantio, pois não foi possível extrair quantidade suficiente de suco da silagem, onde são analisados estes parâmetros. Os valores de $\mathrm{pH}$ aumentaram de 4,1 para 4,9 e 5,1 para as épocas 100, 107 e 114 dias após plantio, respectivamente. Os valores de $\mathrm{N}-\mathrm{NH}_{3} / \mathrm{NT}$ foram próximos ou inferiores aos 10\% recomendados para silagens de boa qualidade.

As equações de regressão entre a digestibilidade (DMS e DMO) e as produções cumulativas de gases (PCG) nos horários de

Tabela 1 - Composição bromatológica, pHe N-NH$/ H_{3}$ NT das silagens de girassol obtidas aos 100,107,114 e 121 dias após plantio

\begin{tabular}{lcccc}
\hline & \multicolumn{4}{c}{ Época de ensilagem } \\
& 100 & 107 & 114 & 121 \\
\cline { 2 - 5 } & 100,4 & 30,3 & 52,5 & 61,6 \\
MS (\%) & 11,0 & 10,6 & 10,7 & 11,3 \\
PB (\%) & 44,8 & 43,3 & 43,9 & 49,1 \\
FDN (\%) & 34,6 & 34,4 & 34,7 & 37,1 \\
FDA (\%) & 7,6 & 6,4 & 8,9 & 7,6 \\
Lignina (\%) & 18,5 & 15,7 & 17,3 & 14,8 \\
EE (\%) & 9,9 & 10,9 & 10,8 & 8,4 \\
Cinzas (\%) & 4,1 & 4,9 & 5,1 & - \\
pH & 7,2 & 11,8 & 7,2 & - \\
N-NH & /NT & &
\end{tabular}

(MS = matéria seca; $\mathrm{PB}=$ proteína bruta; FDN = fibra detergente neutro; $\mathrm{FDA}$ = fibra detergente ácido; $\mathrm{EE}$ = extrato etéreo; e N-NH $\mathrm{NT}=$ nitrogênio amoniacal como parte do nitrogênio total)

$6,12,24,48$ e 96 horas foram significantes $(\mathrm{P}<0,05)$ e encontram-se na tabela 2.

Todos os coeficientes de determinação $\left(R^{2}\right)$ foram elevados, demonstrando que para cada época de ensilagem avaliada (100, 107, 114 e 121 dias após plantio), o volume de gases produzido refletiu o processo de degradação da MS e MO.

As produções cumulativas de gases para a MS e MO das silagens do girassol M734 nas diferentes épocas de ensilagem, encontram-se na tabela 3. As degradabilidades no tempo de incubação de seis horas foram semelhantes $(\mathrm{P}>0,05)$ para as diferentes épocas de ensilagem avaliadas para a $\mathrm{MO}$, porém para a MS as silagens obtidas com 107 dias após 
plantio apresentaram produções cumulativas superiores às obtidas com 114 e 121 dias.

A partir das seis horas de incubação houve redução significativa $(\mathrm{P}<0,05)$ para as produções cumulativas de gases com o avanço do estádio de maturação das plantas, tanto para a MO como para a MS. Numericamente as

Tabela 2 - Equações de regressão entre os valores de digestibilidade (da matéria seca $=\mathrm{DMS}$; e matéria orgânica $=\mathrm{DMO}$ ) obtida pela filtragem dos resíduos de fermentação e produção cumulativa de gases

\begin{tabular}{cccc}
\hline Época & & Equações & $\mathrm{R}^{2}$ \\
\hline \multirow{2}{*}{100} & MS & PCG $=0,573$ DMS $-116,58$ & 0,91 \\
& MO & PCG $=0,547$ DMO $-113,28$ & 0,98 \\
\hline \multirow{2}{*}{107} & MS & PCG $=0,5644$ DMS $-108,14$ & 0,99 \\
& MO PCG $=0,5891$ DMO $-115,10$ & 0,99 \\
\hline \multirow{2}{*}{114} & MS & PCG $=0,5503$ DMS $-98,022$ & 0,97 \\
& $M O$ & PCG $=0,5244$ DMO $-93,188$ & 0,99 \\
\hline \multirow{2}{*}{121} & MS & PCG $=0,4757$ DMS - 66,869 & 0,99 \\
& MO PCG $=0,4511$ DMO - 63,318 & 0,98 \\
\hline
\end{tabular}

produções de gases observadas para a $\mathrm{MO}$ foram superiores às observadas para a MS, já que a produção cumulativa de gases oriundos da MS computa as cinzas, fração que não contribuem para a produção de gases.

$\mathrm{Na}$ comparação das produções de gases entre os períodos de incubação, nota-se aumento significativo com o decorrer dos processos de degradação, porém, as produções cumulativas de gases demonstraram uma tendência de estabilização após 72 horas, sendo o tempo máximo de incubação (96 horas) suficiente para que o máximo de degradação fosse atingido.

Letras maiúsculas idênticas significam semelhança estatística $(\mathrm{P}>0,05)$ em uma mesma linha; letras minúsculas idênticas representam semelhança estatística em uma mesma coluna (MS: $\mathrm{CV}=2,1 ; \mathrm{MO}: \mathrm{CV}=$ $4,0)$.

As diferenças citadas anteriormente podem ser melhor visualizadas na figura 1 , onde são observadas as curvas de produção cumulativa de gases da MS e da MO das silagens de girassol do híbrido M734 ensilados aos 100, 107, 114 e 121 dias após o florescimento.

Nota-se a superioridade das curvas obtidas para as silagens na primeira época (100 dias após o plantio), seguidas pelas curvas das silagens obtidas com 107, 114 e 121 dias.

$\mathrm{Na}$ figura 2, observa-se o gráfico das

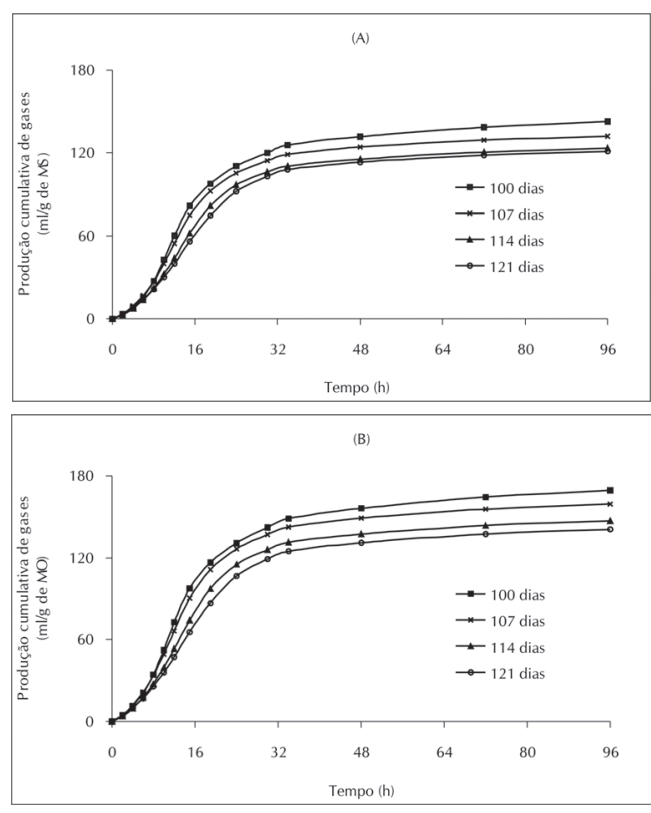

Figura 1 - Produções cumulativas de gases da matéria seca (A) e matéria orgânica (B) das silagens de girassol do híbrido M734, em diferentes épocas de ensilagem $(100,107,114$ e 121 dias após o plantio)

produções de gases por hora das silagens do híbrido M734 obtidas aos 100, 107, 114 e 121 dias após o plantio nos diferentes tempos de fermentação.

As maiores produções de gases por hora foram obtidas aproximadamente às seis horas de fermentação, fato provavelmente ligado à fermentação dos carboidratos prontamente disponíveis. Já entre os períodos de 14 e 24 horas observa-se uma segunda elevação na produção de gases por hora que provavelmente está relacionada à fermentação dos carboidratos fibrosos.

$\mathrm{Na}$ comparação entre as épocas, nota-se as maiores produções de gases por hora para os materiais ensilados mais cedo (100 e 107 dias após o florescimento). Os dois pontos de elevação das produções de gases por hora sofreram grandes oscilações entre as épocas de ensilagem avaliadas, para 
Tabela 3 - Produções cumulativas de gases corrigidas para um grama de matéria seca (PCGMS) e matéria orgânica (PCGMO) após 6, 12, 24 , 48, 72 e 96 horas de fermentação das silagens (em mL/g de MS ou MO) do híbrido de girassol M734 avaliadas em quatro diferentes épocas (100, 107, 114 e 121 dias após o plantio)

\begin{tabular}{|c|c|c|c|c|c|c|}
\hline \multirow[b]{2}{*}{ Épocas } & \multicolumn{6}{|c|}{ Períodos de fermentação } \\
\hline & 6 & 12 & 24 & 48 & 72 & 96 \\
\hline \multicolumn{7}{|l|}{ PCGMS } \\
\hline 100 & $16,6^{\text {Fab }}$ & $62,3^{\mathrm{Ea}}$ & $111,4^{\mathrm{Da}}$ & $132,9^{\mathrm{Ca}}$ & $139,5^{\mathrm{Ba}}$ & $143,7^{\mathrm{Aa}}$ \\
\hline 107 & $18,3^{\mathrm{Ea}}$ & $58,1^{\mathrm{Db}}$ & $108,5^{\mathrm{Ca}}$ & $127,1^{\mathrm{Bb}}$ & $132,1^{\mathrm{Ab}}$ & $135,1^{\mathrm{Ab}}$ \\
\hline 114 & $14,2^{\mathrm{Eb}}$ & $45,6^{\mathrm{Dc}}$ & $97,3^{\mathrm{Cb}}$ & $116,1^{\mathrm{Bc}}$ & $121,1^{\mathrm{Ac}}$ & $124,0^{\mathrm{Ac}}$ \\
\hline 121 & $13,2^{\mathrm{Eb}}$ & $39,2^{\text {Dd }}$ & $90,6^{\mathrm{Cc}}$ & $111,4^{\mathrm{Bd}}$ & $116,5^{\text {Ad }}$ & $119,6^{\mathrm{Ad}}$ \\
\hline \multicolumn{7}{|l|}{ PCGMO } \\
\hline 100 & $20,5^{\mathrm{Ea}}$ & $73,9^{\mathrm{Da}}$ & $131,0^{\mathrm{Ca}}$ & $156,3^{\mathrm{Ba}}$ & $164,4^{\mathrm{Aa}}$ & $169,4^{\mathrm{Aa}}$ \\
\hline 107 & $23,4^{\mathrm{Ea}}$ & $71,5^{\mathrm{Da}}$ & $131,7^{\mathrm{Ca}}$ & $154,4^{\mathrm{Ba}}$ & $160,9^{\mathrm{ABa}}$ & $164,6^{\mathrm{Aa}}$ \\
\hline 114 & $18,0^{\text {Ea }}$ & $55,4^{\mathrm{Db}}$ & $116,2^{\mathrm{Cb}}$ & $138,7^{\mathrm{Bb}}$ & $145,1^{\mathrm{ABb}}$ & $148,6^{\mathrm{Ab}}$ \\
\hline 121 & $16,2^{\mathrm{Ea}}$ & $46,7^{\mathrm{Dc}}$ & $105,7^{\mathrm{Cc}}$ & $130,0^{\mathrm{Bc}}$ & $136,2^{\mathrm{ABC}}$ & $139,8^{\mathrm{Ac}}$ \\
\hline
\end{tabular}

Letrasmaiúsculas idênticas significam semelhança estatística $(P>0,05)$ em uma mesma linha; letras minúsculas idênticas representam semelhança estatística em uma mesma coluna (MS: CV $=2,1 ; \mathrm{MO}: \mathrm{CV}=4,0)$

as silagens obtidas aos 100 e 107 dias após o plantio, as altas produções de gases por hora (relacionadas aos carboidratos rapidamente fermentáveis) na primeira elevação nos gráficos (Figura 2) foram superiores aos valores encontrados para a segunda elevação (associada à fermentação dos carboidratos fibrosos). $\mathrm{O}$ avanço do estádio de maturação das plantas causou modificação nesta relação, notando-se
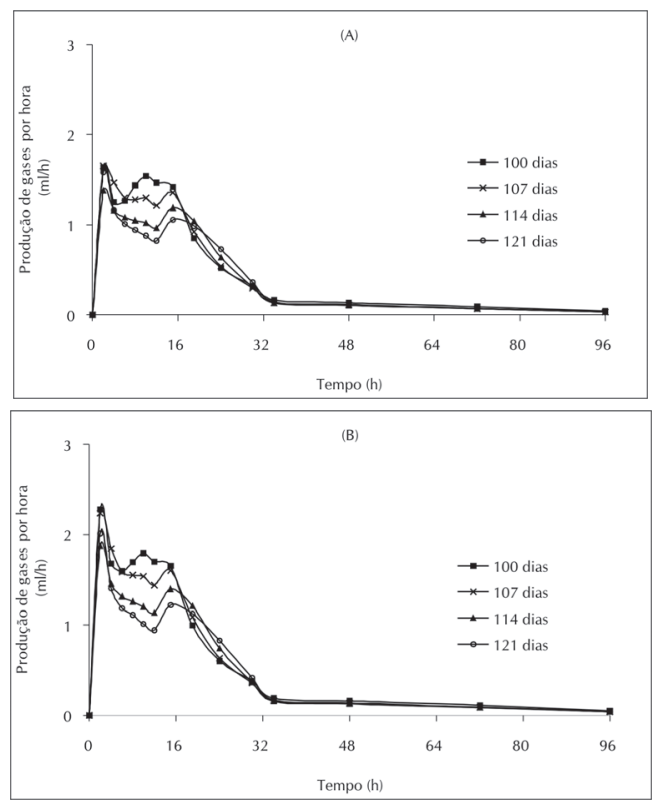

Figura 2 - Produção de gases por hora da matéria seca (A) e matéria orgânica (B) das silagens de girassol do híbrido M734, em diferentesépocas de ensilagem (100,107,114 e 121 dias após o plantio) nas épocas em que o material foi ensilado com 114 e 151 dias após o plantio, que o segundo ponto de elevação atingiu valores mais próximos dos observado no primeiro ponto de elevação. Estas modificações refletem na diminuição do valor nutritivo das silagens, pois com o avançar do estádio de maturação das plantas, provavelmente ocorreu elevação do conteúdo de carboidratos estruturais, que são menos digestíveis que os componentes solúveis da planta.

Os parâmetros da cinética de produção de gases, determinados pelo modelo unicomparimental ${ }^{9}$, referentes à matéria seca $\mathrm{e}$ matéria orgânica das silagens do híbrido de girassol M734, encontram-se na tabela 4.

Os potenciais máximos de produções de gases variaram de 139 a $163 \mathrm{~mL}$ para o MO e de 119 a $138 \mathrm{~mL}$ para a MS. A ensilagem mais tardia levou a redução no potencial máximo de produção de gases $(A)$, parâmetro este que expressão a máxima degradação ruminal de um alimento, sem considerar a limitação do tempo de permanência da digesta no rúmen.

Os trabalhos de avaliação de silagens de girassol pela técnica in vitro semi-automática de produção de gases são praticamente inexistentes. Em avaliação da silagem de girassol associada ou não a silagem de milho foi encontrado o valor de $162 \mathrm{~mL}$ para o $A$ do tratamento que continha apenas a silagem 
Tabela 4- Parâmetros da cinética de produção de gases da matéria seca (MS) e matéria orgânica (MO) das silagens de girassol do híbrido M734 ensilado aos 100, 107,114 e 121 dias após o plantio

\begin{tabular}{|c|c|c|c|c|c|}
\hline & & \multicolumn{4}{|c|}{$\begin{array}{l}\text { Época de ensilagem } \\
\text { (Dias após plantio) }\end{array}$} \\
\hline & & 100 & 107 & 114 & 128 \\
\hline \multirow[t]{2}{*}{$\begin{array}{l}\mathrm{A} \\
(\mathrm{ml})^{1}\end{array}$} & $\mathrm{MO}$ & 163 & 155 & 144 & 139 \\
\hline & MS & 138 & 129 & 121 & 119 \\
\hline \multirow{2}{*}{$\mathrm{L}(\mathrm{h})^{2}$} & $\mathrm{MO}$ & 2,41 & 2,46 & 2,83 & 2,88 \\
\hline & MS & 2,46 & 2,54 & 2,98 & 2,99 \\
\hline \multirow[t]{2}{*}{$\mu(/ h)^{3}$} & $\mathrm{MO}$ & 0,023 & 0,022 & 0,017 & 0,018 \\
\hline & MS & 0,022 & 0,020 & 0,015 & 0,016 \\
\hline
\end{tabular}

${ }^{1}$ Potencial máximo de produção de gases, ${ }^{2}$ tempo de colonização; ${ }^{3}$ taxa de produção de gases, estimados pelo modelo de France et al (1993)

de girassol ${ }^{11}$, valor superior ao observado para as silagens do presente trabalho. O valor de $A$ de $251 \mathrm{~mL}$ para a silagem de milho ${ }^{11}$, e $194 \mathrm{~mL}$ para silagem de sorgo ${ }^{12}$ são superiores ao do presente trabalho, entretanto estas comparações devem ser evitadas e restritas a grupos de alimentos de características próximas, como silagens de girassol. Pois a relação propionato/acetato, resultante da fermentação de um alimento, pode interferir no volume de gases, podendo haver maior ou menor produção, dependendo das relações entre os ácidos graxos voláteis produzidos. Na estequiometria da fermentação das hexoses ${ }^{13}$, nota-se a ausência de produção de $\mathrm{CO}_{2}$ quando é formado o propionato, porém quando a fermentação é direcionada para a formação de acetato e butirato este gás é produzido.

A silagem de girassol, quando comparada com outras forrageiras, como o milho e sorgo, apresentam produções de gases inferiores, uma vez que seus elevados teores de proteína e lipídios não têm participação efetiva na produção de gases ${ }^{14,15}$.

O parâmetro tempo de colonização (L) também foi afetado negativamente com o avanço do estádio de maturação das plantas e oscilaram de 2,41 a 2,88 horas para a $\mathrm{MO}$ e de 2,46 a 2,99 horas para a MS. O avançar da época de ensilagem foi acompanhado pela elevação do $L$, que provavelmente está associado à diminuição dos teores de substratos prontamente fermentáveis e/ou a modificações morfofisiológicas da estrutura da parede celular, como o aumento no conteúdo de sílica, cutina e a possíveis alterações intrinsecas da celulose (grau de condensação e cristalinidade) que serviram como obstáculo para a colonização bacteriana. Valor de $L$ inferior aos obtidos por este experimento foi o de 1,04 horas encontrado também para silagem de girassol do híbrido M734 ensilado em estádio avançado de maturação ${ }^{11}$.

As taxas de produção de gases variaram de 0,016 a $0,022 \mathrm{~mL} / \mathrm{h}$ para a MS e de 0,018 a 0,023 para a MO. Como para o parâmetro $A$, a $m$ também diminuiu com o avanço do estádio de maturação das plantas e, já que forrageiras de boa qualidade apresentam altos valores de degradabilidade potencial e elevadas taxas de degradação, as silagens do híbrido M734 obtidas em estádios mais precoces (100 e 107 dias após plantio) provavelmente apresentem maior potencial nutritivo para alimentação dos ruminantes.

Para confirmar a superioridade ou inferioridade de um ou de outro tratamento a degradabilidade efetiva é um parâmetro importante, pois inclui a taxa fracional de passagem do alimento no cálculo da degradabilidade. Os valores encontrados, adotando-se as taxas de passagem de 0,02, 0,05 e $0,08 / \mathrm{h}$ para as silagens do presente trabalho estão na tabela 5 .

Houve redução nos valores de degradabilidade efetiva da MS e MO para todas as taxas de passagem, com o avançar do estádio de maturação das plantas. A redução nos valores de degradabilidade efetiva da MS e MO com o avançar do estádio de maturação das plantas sugerem a ensilagem da cultura do girassol em estádios mais precoces, esta prática, poderia ser limitada pela baixa qualidade de silagens obtidas com teores de matéria seca muito baixos, porém, alguns trabalhos apontaram a possibilidade de obtenção de silagens de girassol de boa qualidade, mesmo com materiais ensilados com elevados teores de umidade ${ }^{16,17,18}$. Sendo assim, a maior limitação, seria a perda de efluentes em materiais com menos de $25 \%$ de matéria seca ${ }^{18}$. 
Tabela 5 - Degradabilidade efetiva para astaxas de passagem de 0,02,0,05 e 0,08/h para a matéria seca (MS) e matéria orgânica (MO) das silagens do híbrido de girassol M734 ensilado aos 100,107,114 e 121 dias após o plantio

\begin{tabular}{lccccc}
\hline & & \multicolumn{5}{c}{$\begin{array}{c}\text { Época de ensilagem } \\
\text { (Dias após plantio) }\end{array}$} \\
\cline { 3 - 5 } & & 100 & 107 & 114 & 128 \\
\hline $0,02 / \mathrm{h}$ & MO & 41,0 & 36,0 & 34,2 & 32,0 \\
& MS & 41,0 & 36,0 & 34,3 & 32,1 \\
\hline $0,05 / \mathrm{h}$ & MO & 29,5 & 25,7 & 23,5 & 21,4 \\
& MS & 29,4 & 25,7 & 26,3 & 21,3 \\
\hline $0,08 / \mathrm{h}$ & MO & 22,3 & 19,3 & 16,7 & 11,8 \\
& $M S$ & 22,1 & 19,3 & 16,3 & 14,6 \\
\hline
\end{tabular}

\section{Conclusões}

As melhores épocas da ensilagem do híbrido M734 foram aos 100 e 107 dias após o plantio, onde foram observados os maiores valores de DMS, DMO, $A, \mu$, DEMS e DEMO e os menores tempos de colonização.

\title{
Evaluation of silages from hybrid m734 of sunflower obteined in diferent cutting times using the semi-automated "in vitro" gas production technique
}

\begin{abstract}
The success on sunflower utilization for ensiling is dependent on the correct cutting time during growing season. The objective of this experiment was to evaluate, by using the in vitro gas production technique, "Reading Pressure Technique", the kinetic of organic matter $(\mathrm{OM})$ and dry matter $(\mathrm{DM})$ of silages from the sunflower hybrid M734 obtained at 100, 107, 114 and 121 days after planting. Headspace gas pressure readings were taken at 2, 4, 6, 8, 10, 12, 15, 19, 24, 30, 36, 48, 72 and 96 hours post-inoculation. An unicompartimental mathematical model was applied to describe the profiles in terms of the potential gas production, lag phase, rate of gas production and effective dry matter degradation which used 2,5 and $8 \% / \mathrm{h}$ rate of passages. It was observed that latter cuttings promoted the reduction on the potential of gas production for $\mathrm{OM}(162,155,144$ and 139 $\mathrm{mL}$ ) and DM $(138,129,121$ and $119 \mathrm{~mL})$; increased of "lag phase" for $\operatorname{OM}(2,4,2,5,2,8$ and $2,9 \mathrm{~h})$ and $\mathrm{DM}(2,46,2,54,2,98$ and 2,99 $\mathrm{h})$; and reduction of rate fermentation for $\mathrm{OM}(0,023,0,022,0,017$ and $0,017 \mathrm{~mL} / \mathrm{h})$ and $\mathrm{DM}(0,022,0,020,0,015$ and $0,016 \mathrm{~mL} / \mathrm{h})$ respectively for 100,107,114 and 121 days after planting. The best cutting time for M734 hybrid were at 100 and 107 days after planting.
\end{abstract}

Key-words:

Ensilage time. Gas production. Silage. Sunflower.

\section{Referências}

$1 \mathrm{KO}, \mathrm{H}$. J. F. Consumo voluntário e digestibilidade aparente das silagens de quatro genótipos (rumbosol 91, m734, c11, s430) de girassol (helianthus annuus). 66 f. 2002. Dissertação (Mestrado em Zootecnia) Escola de Veterinária, Universidade Federal de Minas Gerais. Belo Horizonte, 2002.

$2 \mathrm{TOMICH}$, T. R. Avaliação do potencial forrageiro e das silagens de treze cultivares de girassol (Helianthus annuus L.). 1999. 131 f. Dissertação (Mestrado em Zootecnia) - Escola de Veterinária, Universidade Federal de Minas Gerais, Belo Horizonte, 1999.

3 MAURICIO, R. M. et al. A semi-automated in vitro gas production technique for ruminant feedstuff evaluation. Animal Feed Science and Technology, v. 
79, n. 4, p. 321-330, 1999.

4 ASSOCIATION OFFICIAL ANALYTICAL CHEMISTS. Official methods of analysis. 13. ed. Washington, $D$. C.: AOAC, 1980. 1015 p.

5 VAN SOEST, P. J.; ROBERTSON, J. B.; LEWIS, B. A. Methods for dietary fiber, neutral detergent, and nonstarch polysaccharides in relation to animal nutrition. Journal Dairy Science, v. 74, n. 10, p. 35833597, 1991.

6 THEODOROU, M. K. et al. A simple gas production method using a pressure transducer to determine the fermentation kinetics of ruminal feeds. Animal Feed Science and Technology, v. 48, n. 3-4, p. 185-197, 1994.

7 MAURÍCIO, R. M. M. et al. Obtenção da equação quadrática entre volume e pressão para a implantação da técnica in vitro semi-automática de produção de gás para avaliação de forrageiras tropicais. In: REUNIÃO ANUAL DA SOCIEDADE BRASIEIRA DE ZOOTECNIA, 38. 2001. Piracicaba. Anais... Piracicaba: SBZ, 2001b. p. 1345-1346.

8 ROSS, G. J. S. Maximun likelihood program Hampendon: Tothmsted Experimental Station, 1980.

9 FRANCE, J. et al. A model to interpret gas accumulation profiles associated with in vitro degradation of ruminant feeds. Journal of Theorical Biology, v. 163, n. 1, p. 99-111, 1993.

10 REPORT of the protein group of the Agricultural Research Council Working party, on the nutrient of ruminants. London: Commonwealth Agricultural Bureaux, 1984. 45 p.

11 LEITE, L. A. et al. Avaliação das silagens de girassol, milho e suas associações pela técnica in vitro semiautomática de produção de gases - 2: Efeitos associativos. In: REUNIÃO ANUAL DA SOCIEDADE BRASILEIRA DE ZOOTECNIA, 39. 2002. Recife. Anais... Recife: SBZ, 2002. CD-ROM.

12 MAURÍCIO, R. M. M. et al. Avaliação das silagens de quatro híbridos de sorgo (Sorghum bicolor (L.) moench) através da técnica "in vitro" semi automática de produção de gás. In: REUNIÃO ANUAL DA SOCIEDADE BRASIEIRA DE ZOOTECNIA, 38. 2001. Piracicaba. Anais... Piracicaba: SBZ, 2001a. p. 13461348.

13 WOLIN, M. J. Interactions between the bacterial species of the rumen. In: MCDONALD, I. W.; WARNER, A.C. (Ed.). Digestion and metabolism in the ruminant. Armidale, Australia: University of New England Publishing Unit, 1975. p. 134-148.

14 CONE, J. W.; VAN GELDER, A. H. Influence of protein fermentation on gas production profiles. Animal Feed Science and Technology. v. 76, n. 3-4, p. 251264, 1999.

15 MENKE, K. H.; STEINGASS, H. Estimation of the energetic feed value obtained from chemical analysis and in vitro gas production using rumen fluid. Animal Research and Development. v. 28, p. 7-55, 1988.

16 EDWARDS, R. A.; McDONALD, P. Fermentation of silage-A review. West Moines: lowa, 1978. 115 p.

17 FREIRE, E. M. Padrão de fermentação das silagens de cinco híbridos de girassol. 2001. 44 f. Dissertação (Mestrado em Zootecnia) - Escola de Veterinária, Universidade Federal de Minas Gerais, Belo Horizonte, 2001.

18 HARPER, F. et al. The potencial of sunflower as a crop for ensilage and zero grazing in northern Britain. Journal of Agricultural Science (Camb.), v. 1, n. 96, p. 45-53, 1981. 